\title{
Advanced medical ethics symposia for fifth-year students
}

\author{
Valerie J Grant Auckland School of Medicine, Auckland, New Zealand
}

\section{Author's abstract}

Case-based, multidisciplinary seminars provided a vehicle for clinicians, philosophers and students to debate current problems in medical ethics in a manner which ensured maximum learning and interest for all participants. Prior training in philosophical medical ethics was an essential prerequisite, giving students the knowledge and skills to take part in the discussions at an appropriate level of sophistication.

\section{Introduction}

Following the recommendations of the Pond Report (1) there appears to be widespread agreement about the need to teach medical ethics (2-5). The problems now are to find the best ways of teaching the necessary material at the various stages in the curriculum. A variety of successful programmes has been described (6-9). There has also been some helpful material on what does not work. For example, Irwin et al (10) found that where students had not had an adequate foundation in general ethical theory, they failed to grasp adequately the presentation of ethical ideas.

\section{Background}

The fifth-year seminars described in this paper are preceded by a programme in philosophical medical ethics during the pre-clinical years. Since 1983, students have had either two or four hours teaching in each of the first three years of their training. Lectures have consisted of basic introductory material in philosophical medical ethics and have been supported by Campbell's (11) and now, Gillon's (12) text-books. Teaching is in time-tabled time and the material is the subject of a compulsory examination question at the end of each year.

Student acceptance is generally high since illustrative material used to clarify issues and problems is taken from topics currently relevant to student work. For example, in the second year issues of confidentiality and informed consent are raised in the ethics teaching, when each student is introduced to a pregnant woman and asked to follow the birth and first

\section{Key words}

Teaching medical ethics. year of life of the child.

By the end of the third year students have some familiarity with the vocabulary of philosophical medical ethics. This vocabulary provides the conceptual tools with which to learn more in discussion and debate. The Pond Report (1) stated that teaching philosophical medical ethics 'may be compared to teaching about scientific method - as opposed to teaching medicine by rote learning'.

\section{Planning the symposia}

At the end of 1987 an interdisciplinary teaching committee in medical ethics was set up by faculty to develop further the existing ethics teaching, and especially to ensure its continuing presence in the clinical years. Since we have yet to acquire a staff member with the appropriate training, it was necessary to incorporate those with some expertise in the planning and carrying out of our advanced sessions.

The design of the symposia was based upon the following decisions:

1. The presence of moral philosophers was essential. The committee acknowledged that unless real expertise, scholarship and a proper philosophicallybased perspective were an integral part of each discussion, the level of debate was likely to deteriorate into mere 'argy bargy', lacking academic rigour. No one questioned either the existence or the availability of such expertise. Again, as the Pond Report (1) has already made plain, this expertise is not new. 'Systematic argument about ethical questions...has been the traditional concern of disciplines such as moral philosophy and moral theology' for a long time. 2. Problems for discussion were to be relevant and real (although suitably disguised to maintain confidentiality) and were to be presented by senior clinicians.

3. There was to be maximum opportunity for discussion between students, clinicians and philosophers, both in small groups and in summing up sessions.

The structure of the symposia was as follows. There was a maximum of 55 students (half the class) at each, three-hour morning symposium. There was a brief 
introduction, reminding students about the nature and content of the medical ethics course over the previous four years. Then four senior clinicians each gave a fiveminute case presentation. Each selected his or her case for its interest and for the difficulty of the ethical problem it presented. Clinicians were asked to use a case which had worried them and one in which even now, they were uncertain about whether the right path had been followed.

After the presentations, students were allocated to one of four groups, each with a clinician and a philosopher consultant. The group sessions began with further elucidation and clarification of the case and the ethical problems it presented. Students were then invited to make suggestions about what they considered would have been an appropriate course of action. The actual outcome was not revealed by the clinician until towards the end of the group session. At every stage in the discussion, the philosopher was asked to point out the implications of the various suggestions made. Sometimes the philosopher was able to clarify points by suggesting slight changes in the problem case.

At the end of the allocated time (one and a quarter hours), students, clinicians and philosophers gathered in the same place for a morning tea break. This gave everyone a chance for informal exchange of ideas and information both between and within groups as well as between staff and students. The last hour was spent in the whole symposium again. A student from each group presented a summary, so that everyone was informed about the different types of cases and the ethical dimensions of each. Each clinician then had a further chance to speak of his or her own experience in the case, and finally the philosophers drew everything together, commenting on the individual cases as well as on their wider implications and their relations to philosophical medical ethics. The symposia were ordered but informal so that students, clinicians and philosophers all felt free to make comments and join in the discussion at any point they wished.

\section{Clinicians and cases}

The clinicians selected were known to be interested, thoughtful, non-rigid and accepting of others' ideas. They also had to be people who did not feel personally threatened at the prospect of students knowing a little more philosophical medical ethics than they did themselves. Since clinicians came from a variety of different specialties, problems and cases covered a wide range of topics.

Members of the interdisciplinary teaching committee had thought that allocation of topics might be necessary, but this proved not to be the case. Clinicians came from obstetrics and gynaecology, surgery, geriatrics, psychiatry, gastro-enterology, general practice, clinical pharmacology and medicine. Cases were mainly patient-centred. The exceptions were two problems raised by the general practice contributor and the clinical pharmacologist. Their cases centred on the behaviour of the doctor. The former concerned problems of confidentiality when working for commercial health maintenance organisations, and the latter ethical dilemmas involving invitations from drug companies.

\section{The philosophers}

Although no member of the department had had any previous experience in this area, the philosophers responded positively to our invitation. They sent two senior lecturers to work with the committee in planning the symposia, and an additional senior lecturer and two doctoral students to act as consultants in the small groups.

The philosophers were the essential ingredient in the success of the symposia. Without them, the discussions would have been little different from those held all the time in clinical settings between groups of concerned medical and other health professionals. It was the contribution of the philosophers which made the symposia the stimulating learning experience they were.

Nor would the programme have worked with naive students. Its success was due at least in part to the fact that students had some background in philosophical medical ethics as well as two years' clinical experience. There was thus a balance in each group, with no one person or group of people having a monopoly on the knowledge required to discuss the issues. There had to be plenty of listening to others' points of view and a genuine sharing of expertise.

\section{Early fears}

Before the symposia began, individuals in each category confided their fears to members of the committee. The clinicians feared they would not be able to justify or explain their courses of action to the philosophers; the philosophers feared their lack of expertise would be apparent, not being as familiar as they would like to have been with current issues in medical ethics. They also feared that their total lack of medical knowledge would prove an insurmountable handicap. Committee members feared that the sessions might not work, or that the not inconsiderable organisational matters might prove faulty. Only the students arrived at the first symposium untroubled.

In the event, everyone's fears were allayed and most people found the sessions stimulating and thoughtprovoking. Neither clinicians nor philosophers hesitated to ask information of one another and these interchanges between experts provided students with good role models for the mutual exchange of views between experts in different disciplines at a high level of sophistication. Students, knowing something of the language of each (philosophical medical ethics and clinical medicine) were often able to help clarify issues, so they too were able to make their own unique contribution.

\section{Assessment and evaluation}

Formal assessment of medical ethics in the clinical 
years is not yet fully co-ordinated at this medical school. Unlike the first three years, in which all the formal assessment of medical ethics is done in the behavioural science examinations, assessment in years four and five is handled by several different departments and in different ways. For example there is an essay in pathology, the topics for which are largely problems in medical ethics, and there are questions in the final examination in community health related to the ethical problems involved in the allocation of resources.

Our experience is that hard pressed medical students must give more study time to those topics that are formally assessed, so although more than seventy per cent of the class attended the symposia without the threat of assessment, we will be examining that in the future. This year there will be a question on medical ethics in the objectively structured clinical examinations (OSCE) and possibly questions in each of the clinical specialty papers as well.

\section{Student evaluation}

At the end of the last symposium, students were requested to complete evaluation questionnaires. They were asked to rate aspects of the symposia on a sevenpoint scale from strong approval (one) to strong disapproval (seven). All aspects were rated positively except 'duration of sessions' where the major complaint was that there was insufficient time. The other aspects were all rated either one or two by the majority of students. These were: the format of the sessions (68 per cent); the range of topics ( 71 per cent); the participation of clinicians ( 89 per cent); the contribution of philosophers (76 per cent), and the overall value of the symposia (65 per cent).

Students were also given the opportunity to write comments if they wished. A large majority of the students wrote favourable comments, saying how much they had enjoyed the symposia and making suggestions for further improvements in the future. One student wrote:

'I was extremely impressed by the philosophers' ability to succinctly and intelligently direct and summarise discussions and hone in on central themes, and by their use of tricks of the trade - for example by slightly changing situations in steps to see where people's positions change - to give an objective focus to the issues being discussed.'

\section{In future}

We will continue to run these symposia, experimenting further in some areas and following up student suggestions.

We would like to make it possible for each student to select the group s/he would prefer to work in, whilst at the same time ensuring that each clinician has at least 12 students in the group.

We will also provide a little more guidance on how to run the groups for those clinicians who would like it.
Some groups were less directed than others, mainly because clinicians modestly held back and asked a student to be the chairperson. It appeared at later review however, that clinicians were thought to be the 'natural' chairpersons, and should confidently take this role.

Students enjoyed, and learned most from, those groups in which clinicians listened sensitively to their suggestions, allowed plenty of time for inter-student discussion, and called for philosopher input on every point as it came up. It became clear to students that clinicians often continue to agonise over decisions taken, and that these senior people, previously regarded as always knowing the answers to everything, were by no means omnipotent and continued to have their own questions and doubts. In the eyes of most students, and all the committee members and philosophers, these clinicians, in allowing their vulnerability to be seen, became more worthy of respect and admiration. As Seedhouse has said: 'Where there is so much uncertainty it is both courageous and practical to acknowledge its existence' (3).

Valerie f Grant MA PhD is Senior Tutor in Behavioural Science and Chairman of the Interdisciplinary Teaching Committee in Medical Ethics, Auckland School of Medicine, Auckland, New Zealand.

\section{References}

(1) Institute of Medical Ethics. Report of a working party on the teaching of medical ethics. Chairman: Sir Desmond Pond. London: IME Publications Ltd, 1987.

(2) Culver C M. Basic curricular goals in medical ethics. New England journal of medicine 1985 ; 312:253-256.

(3) Seedhouse D. The teaching of medical ethics. Fournal of the Royal College of General Practitioners 1987; 37:388389.

(4) Doxiadis S A. The teaching of medical ethics. Medical education. 1988; 22:85-87.

(5) Benatar S R, Jenkins T. Teaching medical ethics in South Africa. South African medical journal. 1988; 73:449-452.

(6) Southgate L J, Heard S R, Toon P D, Salkind M R. A student-led approach to teaching. Fournal of medical ethics 1987; 13:139-143.

(7) Brazier M, Dyson A, Harris J, Lobjoit M. Medical ethics in Manchester. Fournal of medical ethics 1987; 13:150-152.

(8) Calman K C, Downie R S. Practical problems in the teaching of ethics to medical students. Fournal of medical ethics 1987; 13:153-156.

(9) Campbell A V. Reflections from New Zealand. Fournal of medical ethics 1987; 13:137-138.

(10) Irwin W G, McClelland R J, Stout R W, Stchedroff M. Multidisciplinary teaching in a formal ethics course for clinical students. Fournal of medical ethics. 1988; 14:125128.

(11) Campbell A V. Moral dilemmas in medicine. Edinburgh: Churchill Livingstone, 1984.

(12) Gillon R. Philosophical medical ethics. Chichester: Wiley, 1986. 